\title{
Unilateral rib notching in Fallot's tetralogy due to systemic-pulmonary collateral vessels
}

\author{
H. O. Wong and A. H. Ang \\ From the Departments of Medicine and Radiology, Faculty of Medicine, University of Malaya
}

A 2I-year-old man with Fallot's tetralogy was found to have rib notching on the right side due to collaterals from the systemic circulation to the right pulmonary artery. An attempt is made to explain this systemicpulmonary communication based on the embryological development of the pulmonary arteries. The patient's exercise tolerance increased during adolescence presumably due to improvement in pulmonary circulation.

\section{Case report}

A 21-year-old Indian man was admitted for an upper respiratory tract infection. He was first noticed to be cyanosed at the age of I year. He had not started to walk until 4 years old and on mild exertion was breathless, cyanosed, and squatted. At the age of 12 years his exercise tolerance began to improve by stages over seven years until he could play goalkeeper in a game of football.

Physical examination on admission showed the usual features of Fallot's tetralogy. A dilated and pulsatile lateral thoracic artery was seen on the right side. His haemoglobin was $18.7 \mathrm{~g} / 100 \mathrm{ml}$ and haematocrit was 63 per cent. The electrocardiogram and chest $x$-ray showed features consistent with the clinical diagnosis except that rib notching was evident on the right side from the third to the eighth ribs (Fig. I).

At cardiac catheterization repeated attempts to pass the catheter into the pulmonary artery failed. On one occasion the catheter passed from the right ventricle into the aorta and the systolic pressures in both were identical. Data obtained are given in the Table. Cardioconray, $50 \mathrm{ml}$, was injected through a No. $8 \mathrm{NIH}$ catheter into the right ventricle. The angiocardiogram showed simultaneous opacification of the main pulmonary artery and the aorta and conspicuous narrowing of the outflow tract in the region of the infundibulum. A ventricular septal defect and a large overriding aorta were visualized. Obstruction of the right pulmonary artery was thought to be present at its origin because serial films showed delayed opacification of the right pulmonary artery from dilated and tortuous collateral vessels which formed a profuse vascular network in the right paramediastinal region. Some of the collaterals were seen to arise from the right subclavian artery and others from the right intercostal arteries. A well-developed but small right main pulmonary artery was seen in delayed films. In order to delineate more clearly the collateral circulation to the right lung $45 \mathrm{ml}$ Cardioconray were injected into the ascending aorta. Very dilated intercostal arteries on the right side were visualized (Fig. 2). Serial films showed these intercostal arteries and branches of the right subclavian artery supplying the right pulmonary artery which showed the normal pattern of branching. In late films the left pulmonary artery and its branches were faintly visualized, probably by contrast which had refluxed from the right side. There was no evidence of any systemic-pulmonary anastomoses on the left side.

\section{Comments}

Unilateral rib notching due to dilated intercostal arteries is a well-recognized radiological finding in association with several conditions. In coarctation of the aorta bilateral rib notching is the common finding, but in cases where the coarctation involved the left subclavian artery or is sited above its origin rib notching occurs only on the right side (MacLaughlin, I95I ; Campbell and Baylis, I956). Kent (1953), Campbell (1958), and Shapiro and Schrire (1964) drew attention to the development of unilateral rib notching after subclavian-pulmonary artery anastomosis in cases of Fallot's tetralogy on the side where the subclavian artery was divided. The other conditions associated with unilateral rib notching have been reviewed by MacLaughlin (195I) and Kent (1953), and these include neurofibromata of the intercostal nerves, cases of aortic incompetence and of hypertension, tuberous sclerosis, and obstruction of the superior vena cava. The association of rib notching with Ebstein's disease was reported by Reynolds (1950) and with congenital absence of a right pulmonary artery by Massumi and Donohoe (1965) and Gwinn and Lee (1970). Unilateral rib notching in cases with Fallot's tetralogy who have not been operated on is less common but has been described by Batchelder and Williams (1948) and Campbell (1958). In one case (Campbell, 1958) the angiocardiogram showed that the arterial 


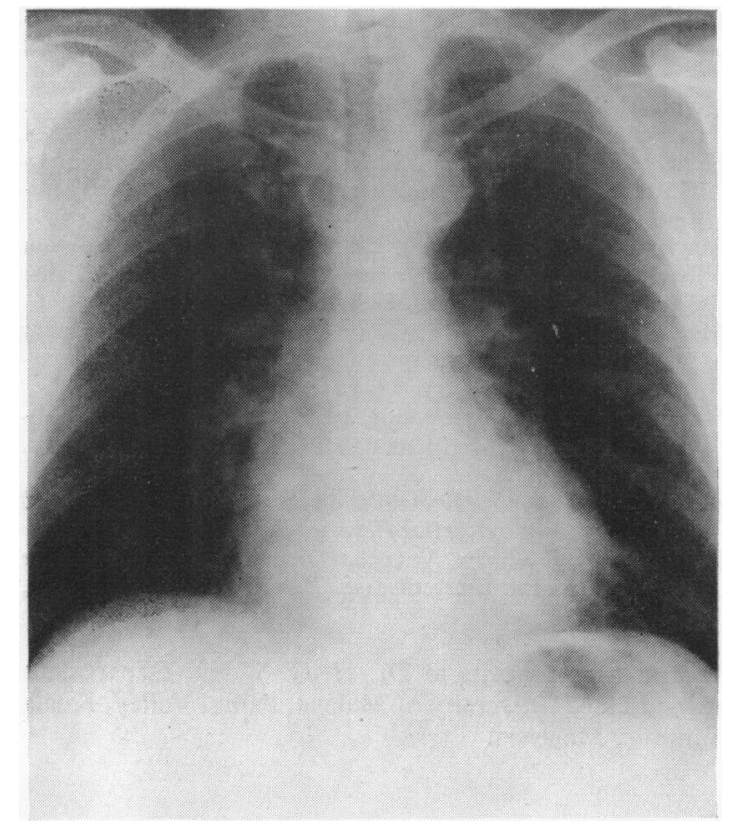

FIG. I Chest $\mathrm{x}$-ray showing rib notching on the right side.

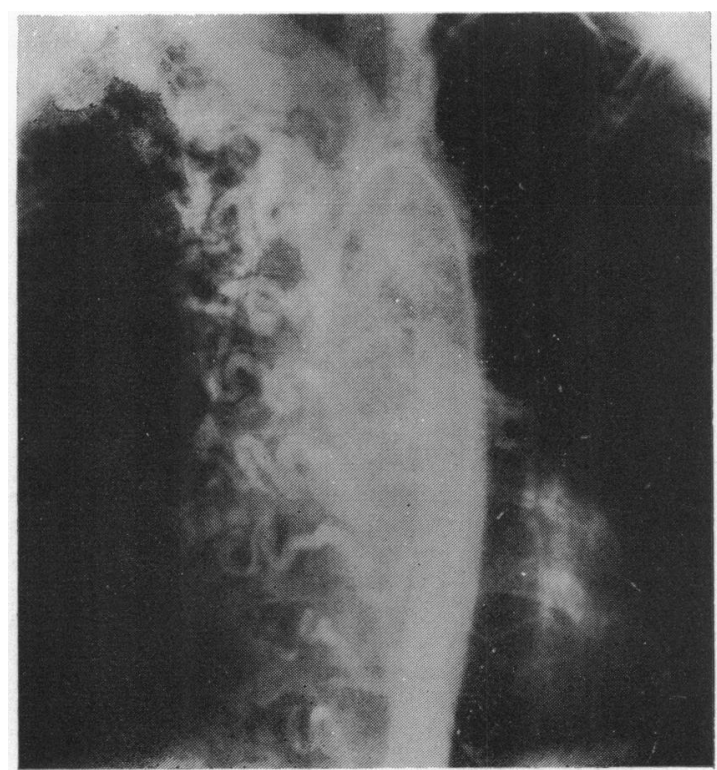

F I G.2 Aortogram showing dilated intercostal arteries on the right side.
TABLE Results of cardiac catheterization

\begin{tabular}{|c|c|c|c|}
\hline \multirow[t]{2}{*}{ Site } & \multicolumn{2}{|c|}{ Pressures $(\mathrm{mmHg})$} & \multirow{2}{*}{$\frac{\text { Oxygen content }}{\% \text { Satn }}$} \\
\hline & Dynamic & Mean & \\
\hline $\begin{array}{l}\text { Right ventricle } \\
\text { Right atrium }\end{array}$ & $\begin{array}{l}120 / 15 / 20 \\
a=15 \\
v=13.5 \\
x=13 \\
y=10\end{array}$ & $\begin{array}{l}60 \\
\text { II }\end{array}$ & $\begin{array}{l}67 \cdot 5 \\
73\end{array}$ \\
\hline $\begin{array}{l}\text { Superior vena cava } \\
\text { Inferior vena cava } \\
\text { Femoral artery }\end{array}$ & $\bar{Z}_{110 / 80}$ & $\frac{-}{100}$ & $\begin{array}{l}64 \\
76 \\
90\end{array}$ \\
\hline
\end{tabular}

supply to the right upper lobe was abnormal and blood appeared to reach this region from branches of the right subclavian artery. No detailed arteriographic studies were carried out. In our patient arteriographic studies revealed the interesting finding of filling of the right pulmonary artery via collaterals from the systemic circulation.

In the embryo the pulmonary arteries develop from the sixth branchial arches. The distal portion on the right side regresses while that on the left side becomes the ductus arteriosus. Hence on the right side there is no direct communication between the right pulmonary artery and the systemic circulation. It is conceivable, however, that if the distal portion of the right sixth branchial arch remains patent this could serve as a channel of communication between the right pulmonary artery and the right subclavian artery, intercostal arteries, and the longitudinal anastomotic channels such as the lateral thoracic and internal mammary arteries. This could explain the mode of blood supply to the right lung in our patient.

A very similar type of arterial communication with the pulmonary artery was described by Arvay, Csakany, and Tomory (1965) in their patient with Fallot's tetralogy and atrial septal defect. There was a communication between the internal mammary and pericardiophrenic artery with the right main pulmonary trunk. Communication between systemic arteries and a main branch of the pulmonary artery is not common. The more usual way for increasing blood supply to an ischaemic lung is via the development of bronchial collaterals and less commonly via systemic arteries which enter the lung parenchyma directly (Maier, 1954). Such systemic-pulmonary anastomoses do not involve the intercostal arteries, and hence do not give rise to rib notching. The decrease in disability during adolescence in our patient is probably due to the development of collateral circulation. A similar improvement was noted in the case described by Reynolds (1950). 


\section{Addendum}

After this paper was submitted for publication a second case of unilateral rib notching was seen in a 31-year-old Chinese male patient who presented with the typical clinical features of Fallot's tetralogy. Angiocardiographic studies showed pulmonary infundibular and valvular stenosis, with hypoplastic right and left main pulmonary arteries. Aortography revealed a well-developed collateral supply to the right lung arising from the right internal mammary, the right lateral thoracic, and the right intercostal arteries. These vessels supplied the right lung, mainly the right upper zone, directly.

\section{References}

Arvay, A., Csakany, G., and Tomory, E. (1965). Systemic arterial/pulmonary arterial communication in a case of Fallot's pentalogy. Acta Radiologica. Diagnosis, 3, 151 .

Batchelder, P., and Williams, R. J. (1948). Notching of ribs without coarctation. Radiology, 5I, 826.

Campbell, M. (1958). Unilateral rib-notching from the collateral circulation after division of the subclavian artery. British Heart fournal, 20, 253.
Campbell, M., and Baylis, J. H. (1956). The course and prognosis of coarctation of the aorta. British Heart fournal, 18, 475.

Gwinn, J. L., and Lee, F. A. (1970). Radiological case of the month. American fournal of Diseases of Children, Ir9, I4I.

Kent, J. V. (1953). The development of rib notching after surgical intervention in congenital heart disease. British fournal of Radiology, 26, 346.

MacLaughlin, J. P. (I95I). Unilateral costal and scapular notching associated with coarctation of the aorta. British Fournal of Radiology, 24, 688.

Maier, H. C. (1954). Absence or hypoplasia of a pulmonary artery with anomalous systemic arteries to the lung. fournal of Thoracic Surgery, 28, 145.

Massumi, R. A., and Donohoe, R. F. (1965). Congenital absence versus acquired attenuation of one pulmonary artery. Circulation, 31, 436.

Reynolds, G. (1950). Ebstein's disease - a case diagnosed clinically. Guy's Hospital Reports, 99, 276.

Shapiro, S., and Schrire, V. (1964). Unilateral notching of the ribs in cyanotic heart disease. British Heart fournal, 26, 620.

Requests for reprints to Dr. H. O. Wong, Department of Medicine, University of Malaya, Pantai Valley, Kuala Lumpur, Malaysia.

\section{Notice}

\section{Third international symposium on atherosclerosis}

The Third International Symposium on Atherosclerosis will be held from 25-28 October 1973 in West-Berlin, Kongresshalle, Germany. General sessions are intended to continue topics from the earlier meetings in Athens (1965) and Chicago (1969) and discuss new developments in pathogenesis, diagnosis, prevention, and therapy of atherosclerosis. In addition, workshops will be held to deal with points of particular interest, including submitted papers whenever possible. Further information can be obtained by writing to Prof. Dr. G. Schettler, c/o International Symposium on Atherosclerosis, Kongressgesellschaft für ärztliche Fortbildung e.V., I Berlin 4I, Wrangelstrasse II-12, Germany. 